\title{
Survey of professionals on breast cancer, fertility preservation and pregnancy in Argentina
}

\author{
Alejandra García ${ }^{1}$, Gabriela Candás ${ }^{1}$, Agustina Bemi ${ }^{1}$, Héctor Daniel Vuoto ${ }^{1}$, Ernesto Korbenfeld ${ }^{3}$, Juan Isetta ${ }^{1}$, Lucas Cogorno ${ }^{1}$, \\ Agustina González Zimmermann ${ }^{1}$, Marcia Sigal ${ }^{1}$, Santiago Acevedo ${ }^{1}$, Julia Berwart ${ }^{1}$, Martín Naveira ${ }^{3}$, María Delfina Ocampo ${ }^{1}$ and \\ Juan Luis Uriburu ${ }^{3}$
}

${ }^{1}$ Mastology Service, British Hospital of Buenos Aires, Perdriel 74, CABA, Buenos Aires C1280AEB, Argentina

${ }^{2}$ Oncology Service, British Hospital of Buenos Aires, Perdriel 74, CABA, Buenos Aires C1280AEB, Argentina

${ }^{3} \mathrm{Head}$, Mastology Service, British Hospital of Buenos Aires, Perdriel 74, CABA, Buenos Aires C1280AEB, Argentina

\begin{abstract}
Introduction: Medical knowledge regarding preservation of fertility and pregnancy in patients with breast cancer (BC) is of interest. We, therefore, decided to conduct a survey on this issue among professionals involved in the treatment of $\mathrm{BC}$ in Argentina.
\end{abstract}

Materials and methods: A survey was conducted and sent by email to 3,412 contacts in the Argentine Mastology Society (Sociedad Argentina de Mastología, or SAM) database, with responses from 396 physicians. The survey design was based on the Lambertini 2017 survey. To the author's knowledge, it is the first Argentine survey to address this issue.

Results: The frequency with which the impact of cancer treatment on the fertility of young patients was addressed by the respondent and referred to a fertility specialist was 'always' and 'almost always' in $86.8 \%$ and $78.5 \%$ of cases, respectively.

Conclusions: The level of knowledge is comparable to the data presented by other surveys. Membership in a Mastology Unit was associated with more current treatment. Continued work on the training of professionals is necessary to facilitate communication, information and guidance of patients of childbearing age who are going to have cancer treatment in order to advise them on fertility preservation, as well as the possibility of pregnancy after diagnosis of $\mathrm{BC}$, and to be able to provide better care to those with $\mathrm{BC}$ associated with pregnancy.

Keywords: survey, medical knowledge, breast cancer, preservation of fertility, breast cancer associated with pregnancy

\section{Introduction}

In the United States from 2013 to 2017, the incidence of breast cancer (BC) in women aged $20-34$ years represented $1.9 \%$ of diagnoses, and those aged $35-44$
Correspondence to: Alejandra M García. Email: algarcia@hbritanico.com.ar

ecancer 2021, 15:1183

https://doi.org/10.3332/ecancer.2021.1183

Published: $10 / 02 / 2021$

Received: 18/09/2020

Publication costs for this article were supported by ecancer (UK Charity number 1176307).

Copyright: $($ ) the authors; licensee ecancermedicalscience. This is an Open Access article distributed under the terms of the Creative Commons Attribution License (http:// creativecommons.org/licenses/by/3.0), which permits unrestricted use, distribution, and reproduction in any medium, provided the original work is properly cited. 
years represented $8.3 \%$. The mortality rates were $0.9 \%$ in women aged $20-34$ years and $4.6 \%$ for those between 35 and 44 years of age [1].

In a collaborative study published in 2016 that included 1,732 patients with BC in Argentina, the incidence by age was 7.4\% for those between 30 and 39 years old and $8.5 \%$ for those between 40 and 44 years old [2]. According to data from the Breast Cancer Registry (Registro de Cáncer de Mama, or RCM) of the Argentine Mastology Society (SAM), 10.4\% of infiltrating carcinomas were found in young women [3].

Globally, deaths from BC have been declining since the late 1980s in both young and older women [4]. According to the statistics published by the Surveillance, Epidemiology and End Results Program (SEER) [1], the age-adjusted rate of new BCs has increased 0.3\% per year in the last 10 years, while mortality decreased $1.5 \%$ annually from 2008 to 2017. The 5-year survival rate has increased, reaching $91.27 \%$ in 2013.

Due to the increased survival of patients and the delay of motherhood for personal and social reasons, it is likely that young women diagnosed with BC have not fulfilled their plans for motherhood at the time of diagnosis, and are interested in their future fertility as well as the possibility of facing BC during pregnancy.

The first doctors to come into contact with young women with BC, whether they are mastologists, gynaecologists or oncologists, must know the needs and particular characteristics of this population. It is they who will have the opportunity to make a timely referral to a fertility specialist, as well as choosing the best therapeutic strategies for those with a diagnosis of BC during pregnancy to carry the foetus to term, without compromising the oncological safety of the mother or vitality and normal development of the foetus.

Today there are international guidelines with different algorithms for the management of young patients who wish to preserve their fertility [4-6], as well as the management of $\mathrm{BC}$ during pregnancy [7, 8], with the aim of providing up-to-date evidence to support medical practice.

According to a recent publication, using data from American Association of Clinical Oncology's (ASCO) Quality in Oncology Practice Initiative [9], only $56 \%$ of women received fertility preservation counselling. According to the guidelines of the ASCO, the National Comprehensive Cancer Network and the European Society for Medical Oncology (ESMO) [5-7], consultations with pre-menopausal patients with BC should include fertility preservation counselling prior to beginning treatment, and no patient should be excluded.

Medical knowledge on these topics is of interest; therefore, surveys have been conducted on this topic in different countries in order to train and educate physicians, thereby improving the quality of advice and care for patients [10-13].

We, therefore, decided to conduct a survey of professionals involved in the treatment of $B C$ in order to analyse the knowledge and current practice in the preservation of fertility and pregnancy in Argentina.

\section{Materials and methods}

A survey (Appendix A) was conducted and sent via email to 3,412 contacts in the Argentine Mastology Society (SAM) database. It was sent three times: 31 July, 25 October25 and 17 December 2019. Five hundred and sixty-one professionals (16.4\%) clicked on the link, and 396 physicians completed the survey ( $11.6 \%$ of the total emails sent, and $70.5 \%$ of those who clicked on the link).

Participation was anonymous and voluntary; consent was implicit when choosing to open the link in the email, which indicated its content (Appendix B).

The survey design was based on Lambertini et al. 2017 [13]. It was modified and adapted, and was divided into four sections. The first section included 11 questions on demographic data. A second section included 11 questions on BC and fertility preservation. The third section included 6 questions about pregnancy after BC, and finally, a fourth included 11 questions about BC during pregnancy. The survey was directed to different specialists involved in the care of patients with BC. 
To the author's knowledge, this is the first Argentine survey that addresses issues in the management of and current practices in BC, preservation of fertility and pregnancy, by the professionals who care for these patients.

\section{Statistical analysis}

The category variables are described using the raw number and the percentage in each category. The Chi square test was performed with Mantel-Haenszel correction. The $p$ value for statistical significance was $<0.05$. The OpenEpi program, version 3.01 , was used to perform the calculations.

\section{Results}

Three hundred and ninety-six responses were received.

\section{Demographic characteristics}

$62.4 \%$ of those surveyed were between 30 and 49 years of age. $87.7 \%$ were gynaecologists or mastologists, $4.5 \%$ were clinical oncologists and $91.4 \%$ said that they would be interested in receiving information on the topic (Table 1).

\section{Fertility preservation}

The impact of cancer treatment on the fertility of young patients was addressed and referred accordingly 'always' and 'almost always' in 344 respondents (86.8\%) and 311 (78.5\%), respectively (Figures 1 and 2 ).

Table 1. Demographic characteristics of individuals polled.

\begin{tabular}{|l|c|c|}
\hline \multicolumn{1}{|c|}{ Total population } & $n$ & $\%$ \\
\hline Age & 396 & $100 \%$ \\
\hline $20-29$ years & 18 & 4.5 \\
\hline 30-39 years & 121 & 30.6 \\
\hline 40-49 years & 126 & 31.8 \\
\hline 50-59 years & 67 & 16.9 \\
\hline 60 or older & 64 & 16.2 \\
\hline Gender & 237 & 59.8 \\
\hline Women & 159 & 40.2 \\
\hline Men & 172 & 43.5 \\
\hline Speciality & 175 & 44.2 \\
\hline Mastology & 18 & 4.5 \\
\hline Gynaecology
\end{tabular}


Table 1. Continued.

\begin{tabular}{|c|c|c|}
\hline Obstetrics & 17 & 4.3 \\
\hline General surgery & 8 & 2 \\
\hline Other & 6 & 1.5 \\
\hline \multicolumn{3}{|l|}{ Usual place of practice } \\
\hline Private practice & 77 & 19.4 \\
\hline Hospital/sanatorium & 121 & 30.6 \\
\hline Both & 195 & 49.2 \\
\hline Other & 3 & 0.8 \\
\hline \multicolumn{3}{|l|}{ Years in practice } \\
\hline $1-5$ years & 71 & 17.9 \\
\hline $6-10$ years & 62 & 15.6 \\
\hline $11-15$ years & 67 & 16.9 \\
\hline $16-20$ years & 56 & 14.1 \\
\hline 20 years or more & 140 & 35.5 \\
\hline \multicolumn{3}{|c|}{ Work in a MU accredited by SAM } \\
\hline Yes & 109 & 27.5 \\
\hline No & 287 & 72.5 \\
\hline \multicolumn{3}{|c|}{ Patients $<40$ years seen annually } \\
\hline Under 10 & 218 & 55.1 \\
\hline $10-50$ & 147 & 37.1 \\
\hline More than 50 & 31 & 7.8 \\
\hline \multicolumn{3}{|c|}{ Patients with $B C$ during pregnancy seen in the last 10 years } \\
\hline None & 81 & 20.5 \\
\hline $1-5$ & 219 & 55.3 \\
\hline $6-10$ & 69 & 17.4 \\
\hline More than 10 & 27 & 6.8 \\
\hline \multicolumn{3}{|c|}{ Interested in receiving information about the topic addressec } \\
\hline Yes & 362 & 91.4 \\
\hline No & 11 & 2.8 \\
\hline Maybe & 23 & 5.8 \\
\hline \multicolumn{3}{|c|}{ Interested in attending a course about the topic addressed } \\
\hline Yes & 285 & 72 \\
\hline No & 25 & 6.3 \\
\hline Maybe & 86 & 21.7 \\
\hline
\end{tabular}

MU: Mastology unit, ASM: Argentine Society of Mastology, PABC: pregnancy-associated BC 


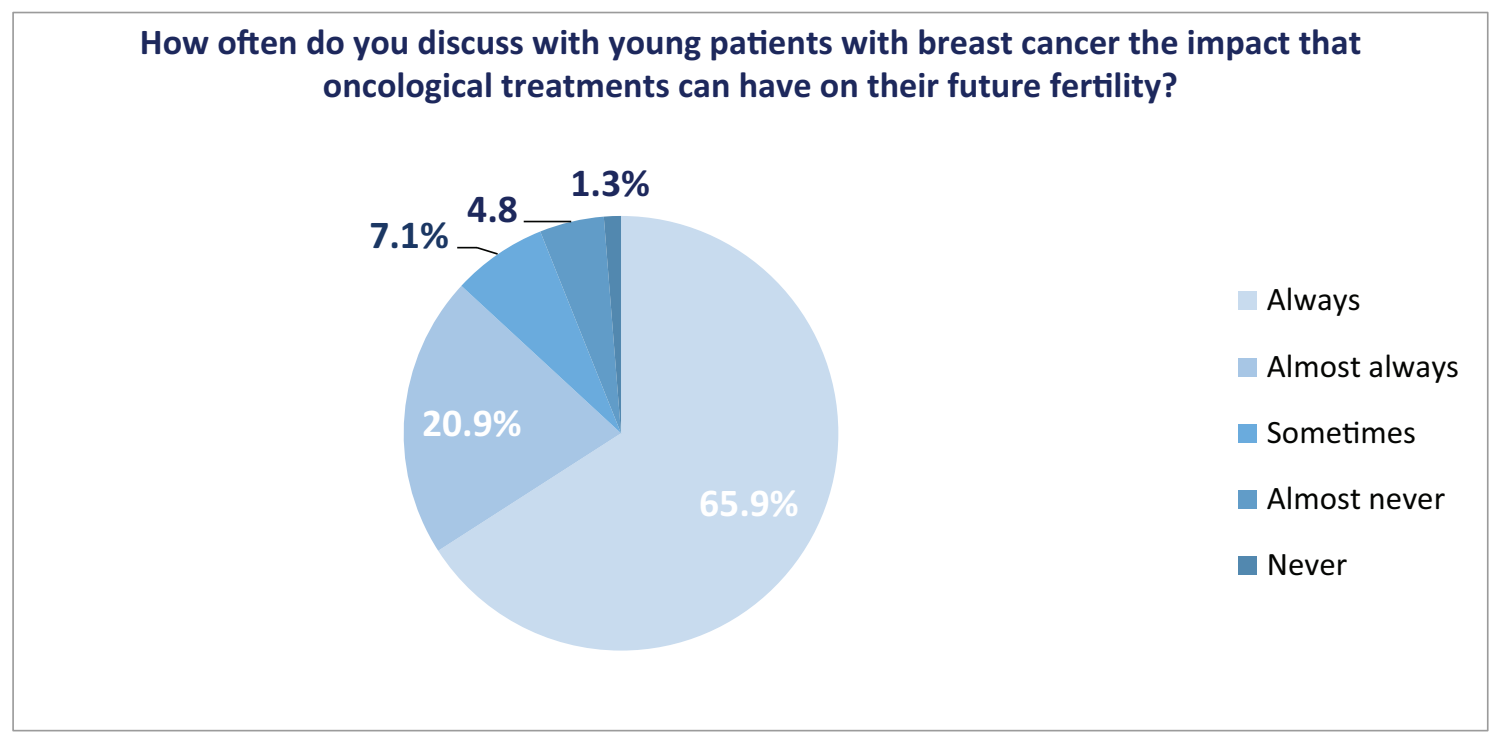

Figure 1. Discussion of the impact of oncological treatment on future fertility.

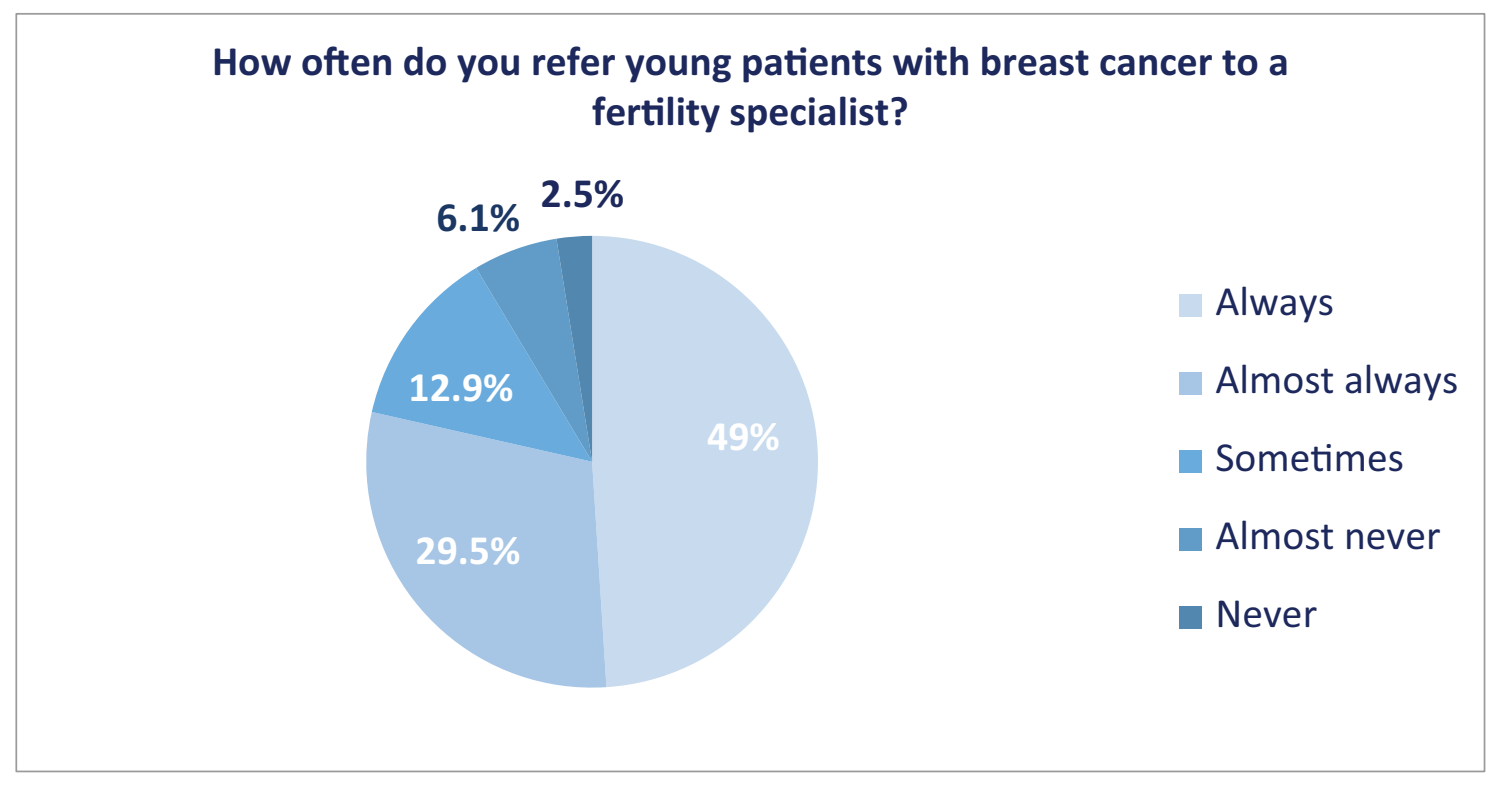

Figure 2. Frequency of referral to a fertility specialist.

In 210 cases, a response was provided for the most frequent reasons why patients were not referred to a fertility specialist: the patient did not desire referral 112 (53.3\%); factors related to the patient: age, parity, marital status, cancer prognosis 85 (40.5\%); there are no fertility specialists in their area 65 (30.9\%); and lack of information on available techniques 24 (11.4\%) (Figure 3).

We did not find statistically significant differences when evaluating the approach to the impact of cancer treatment on fertility $(p=0.6)$ and referral ( $p=0.9$ ), according to the speciality of the respondent: gynaecologist: always or almost always discuss $86.8 \%$ and provide referral 80.6\%; mastologist: $90.1 \%$ and $79.6 \%$; and oncologist: $94.4 \%$ and $77.8 \%$. 


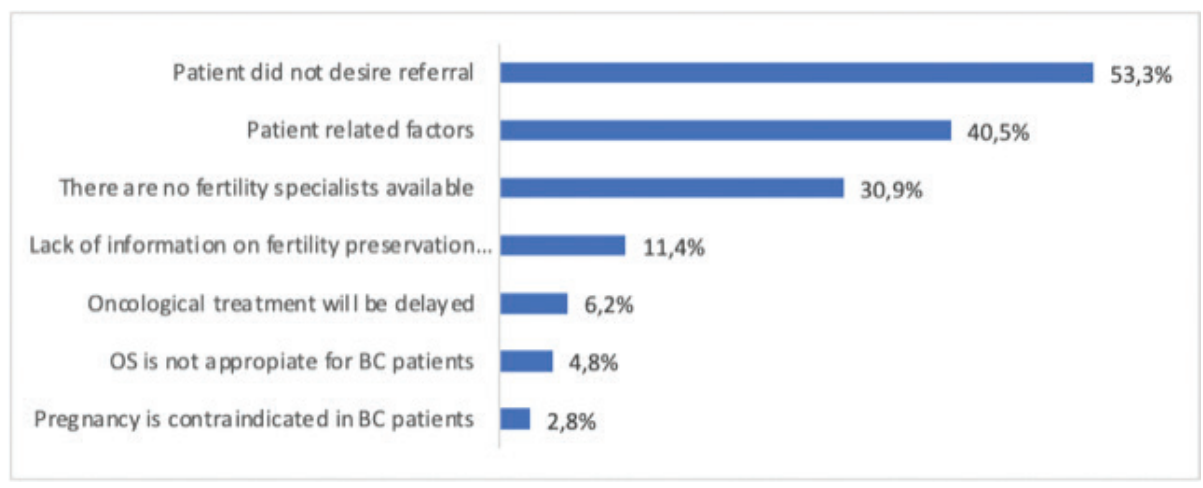

Figure 3. Reason for not referring patients to a fertility specialist. ( $n$ : 210$)$. OS = Ovarian stimulation; pt = patient; $B C=$ breast cancer.

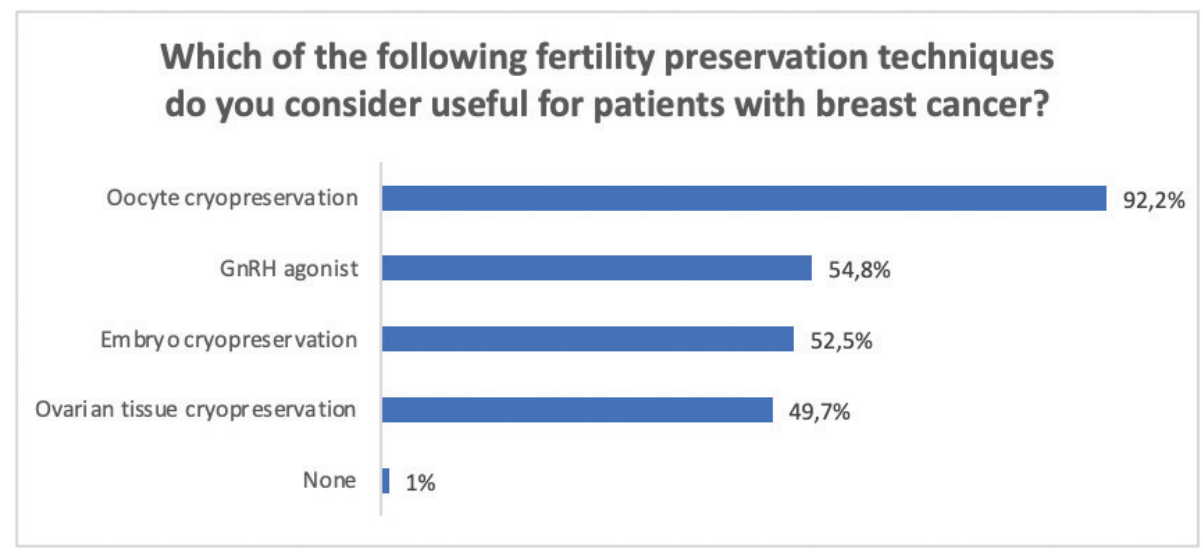

Figure 4. Knowledge regarding utility of different techniques of fertility preservation in patients with BC. BC = Breast cancer; $\mathrm{CT}=$ chemotherapy .

Regarding fertility preservation techniques, the majority, 365 (92.2\%) considered oocyte cryopreservation useful (Figure 4).

The responses regarding the safety of ovarian stimulation (OS) and the impact of cancer treatments on fertility are detailed in Table 2.

\section{Pregnancy after BC}

When evaluating the risk posed by pregnancy after BC, $66.2 \%$ of those surveyed affirmed that the risk does not increase, $45.2 \%$ considered that it does not do so within the first 2 years of diagnosis or with positive oestrogen receptor (ER) disease (58.3\%) (Table 3).

51.3\% considered it safe to temporarily interrupt hormone therapy (HT) after 18-30 months to attempt a pregnancy.

\section{BC associated with pregnancy}

$39.9 \%$ of those surveyed answered that BC during pregnancy, even when treated properly, has a worse prognosis. $33.6 \%$ stated that patients diagnosed at 28-33 weeks should be indicated a preterm delivery (PD) to begin cancer treatment (Table 4).

Regarding the identification of the sentinel node, $28.5 \%$ and $52 \%$ considered the use of patent blue and radiocolloids safe, respectively.

When evaluating the safety of the different adjuvant treatments, we see that $66.4 \%$ considered chemotherapy (CT) safe from the second trimester on; $85.6 \%, 74.7 \%$ and $62.1 \%$ did not consider the use of radiation treatment (RT), HT and anti-HER2 therapies to be safe. 
Table 2. Fertility preservation.

\begin{tabular}{|c|c|c|c|}
\hline & Yes & No & NR \\
\hline OS is considered safe in all patients with $\mathrm{BC}$ & $180(45.5 \%)$ & $101(25.5 \%)$ & 115 (29\%) \\
\hline OS is considered safe in patients with ER positive BC & $168(42.4 \%)$ & $98(24.8 \%)$ & $130(32.8 \%)$ \\
\hline OS is considered safe in patients who have received neoadjuvant CT & $198(50 \%)$ & $69(17.4 \%)$ & 129 (32.6\%) \\
\hline OS in patients with a BC diagnosis should include letrozole or tamoxifen & $203(51.3 \%)$ & $37(9.3 \%)$ & $156(39.4 \%)$ \\
\hline $\begin{array}{l}\text { The use of analogues during } \mathrm{CT} \text { can be offered to all pre-menopausal patients } \\
\text { with } \mathrm{BC} \text { who wish to preserve their fertility independent of ER status }\end{array}$ & $249(62.9 \%)$ & $52(13.1 \%)$ & $95(24 \%)$ \\
\hline The impact of CT on future fertility depends on age, drugs and dosages used & $350(88.4 \%)$ & $13(3.3 \%)$ & $33(8.3 \%)$ \\
\hline $\begin{array}{l}\text { The risk of amenorrhoea following CT is greater in women }<30 \text { years } \\
\text { compared to women }>40 \text { years }\end{array}$ & $88(22.2 \%)$ & $245(61.9 \%)$ & 63 (15.9\%) \\
\hline
\end{tabular}

OS: Ovarian stimulation, pts: patients, BC: breast cancer, ER: oestrogen receptors, CT: chemotherapy, NR: no response

Table 3. Pregnancy after BC.

\begin{tabular}{|c|c|c|c|}
\hline & Yes & No & NR \\
\hline Pregnancy after BC increases RR & $77(19.4 \%)$ & $262(66.2 \%)$ & $57(14.4 \%)$ \\
\hline Pregnancy after BC increases RR only in the first 2 years following $d x$ & $127(32.1 \%)$ & $179(45.2 \%)$ & $90(22.7 \%)$ \\
\hline Pregnancy after BC increases RR only in ER positive cancers & $64(16.2 \%)$ & $231(58.3 \%)$ & $101(25.5 \%)$ \\
\hline $\begin{array}{l}\text { It is considered safe to temporarily interrupt HT after } 18-30 \text { months to allow } \\
\text { a pregnancy }\end{array}$ & $203(51.3 \%)$ & $79(19.9 \%)$ & $114(28.8 \%)$ \\
\hline Lactation after BC is considered safe & $313(79 \%)$ & $22(5.6 \%)$ & $61(15.4 \%)$ \\
\hline ARTs are considered safe in patients who have had BC & $247(62.4 \%)$ & $44(11.1 \%)$ & $105(26.5 \%)$ \\
\hline
\end{tabular}

BC: breast cancer, RR: risk of recurrence, dx: diagnosis, ER: oestrogen receptors, HT: hormone therapy, ART: assisted reproduction techniques, NR: no response

Table 4. BC associated with pregnancy.

\begin{tabular}{|c|c|c|c|}
\hline & Yes & No & NR \\
\hline PABC, even when adequately treated, has a worse prognosis & $158(39.9 \%)$ & $205(51.8 \%)$ & $33(8.3 \%)$ \\
\hline In patients diagnosed between 28 and 33 weeks, a PD is indicated & $133(33.6 \%)$ & $208(52.5 \%)$ & 55 (13.9\%) \\
\hline Mx may be used with abdominal protection & $368(92.9 \%)$ & $18(4.6 \%)$ & $10(2.5 \%)$ \\
\hline Conservative surgery may be considered, depending on the case & $331(83.6 \%)$ & $45(11.4 \%)$ & $20(5 \%)$ \\
\hline SNB with patent blue may be used, depending on the case & $113(28.5 \%)$ & $221(55.8 \%)$ & $62(15.7 \%)$ \\
\hline SNB with radiocolloids may be performed, depending on the case & $206(52 \%)$ & $116(29.3 \%)$ & $74(18.7 \%)$ \\
\hline RT during pregnancy is safe & $10(2.5 \%)$ & $339(85.6)$ & $47(11.9 \%)$ \\
\hline CT may be used safely in any trimester & $7(1.8 \%)$ & $359(90.6 \%)$ & $30(7.6 \%)$ \\
\hline CT may be used safely from the second trimester on & $263(66.4 \%)$ & $72(18.2 \%)$ & $61(15.4 \%)$ \\
\hline HT may be used safely & $28(7.1 \%)$ & $296(74.7 \%)$ & $72(18.2 \%)$ \\
\hline Anti-Her2 treatment may be used safely & $28(7.1 \%)$ & $246(62.1 \%)$ & $122(30.8 \%)$ \\
\hline
\end{tabular}

PABC: Pregnancy-associated BC, dx: diagnosis, PD: preterm delivery, Mx: mammogram, SNB: sentinel node biopsy, RT: radiation therapy, CT: chemotherapy, NR: no response 


\section{Evaluation according to membership in a Mastology Unit (MU)}

$13.8 \%(n=15)$ of the professionals who work in a Mastology Unit (MU) do not have fertility specialists in their area, nor do $17.4 \%$ ( $n=50)$ of those who do not work in a MU; this difference was not statistically significant ( $p=0.7$ ) (Table 5).

Eighteen questions were selected according to the clinical relevance of the knowledge. The responses were analysed, taking into consideration whether or not the respondent belonged to a MU and whether they were in accordance with current guidelines and recommendations [4-8].

We found a statistically significant difference in those professionals who belonged to these units in 16 of the 18 questions evaluated.

\section{Discussion}

The future fertility and oncological safety of a patient with a pregnancy following BC diagnosis are important issues for many young women [14]. The knowledge of the physicians who treat these patients is essential to provide adequate information in the decision-making process and improve the quality of care.

\section{Fertility preservation}

In our survey, we observed that $86.8 \%$ of treating physicians address the impact that cancer treatment will have on the fertility of young patients. Although it is an important percentage, it was lower than that published in the literature, which reports values between $91.6 \%$ and $98 \%[11-14]$.

Referral to a fertility specialist has evolved over time: in the surveys conducted by Quinn in 2009 [10] and Forman in 2010 [11], it was specified in only $47 \%$ and $39 \%$. The inclusion of this topic in the guidelines surely contributed to a favourable change, as evidenced by Adams in 2013 [12], where referral reached 67\%, reaching 97\% according to Rosenberg in 2017 [14]. In our study, referrals were given in 78.5\% of cases, and although this is an overall improvement, it remains sub-optimal.

The most frequent reason for lack of referral was that the patient did not want it (53.3\%), and factors related to the patient: age, parity, marital status, cancer prognosis (40.5\%), similar to that published by Lambertini et al [13], who found that these factors are the main barrier to accessing consultation with a fertility specialist (53.8\%). However, according to Forman et al [11], these factors should not deprive a patient of the discussion regarding fertility preservation.

When evaluating patient surveys by Ruddy [15] and Partridge [16], future fertility is a matter of great concern, which may even impact their therapeutic decisions $[17,18]$. Therefore, it is striking that one of the most frequent causes of lack of referral is that the patient does not want it. It is worth questioning how we inform patients on this topic, and how our beliefs, opinions or lack of knowledge impact that decision, as, according to that published by Peate et al [19], 75\% of the patients base their decision on the opinion of their doctor.

The absence of fertility specialists and the lack of information on available techniques were other causes of the lack of referral, data that coincide with that published by Lambertini (30.9\% versus $28.2 \%$ and $11.4 \%$ versus $17.9 \%$ ) [13]. It must be mentioned that in Argentina, public and private institutions have their own fertility services or access these services following the concept of MUs without borders.

It is encouraging that $91.4 \%$ of the respondents wish to receive information on the subject and $72 \%$ would attend a course, similar to that published by Forman [11].

In the study conducted by Masciello et al [20], 78\% of mastologists prefer to defer the discussion about fertility preservation for the Oncologists to address. On the other hand, we did not find statistically significant differences between the different professionals involved.

Nearly all of the respondents (92.2\%) considered oocyte cryopreservation, one of the currently most recommended techniques, to be useful [5]. However, a lack of knowledge of different techniques, between $7.8 \%$ and $50.3 \%$, is observed. 
Table 5. Knowledge according to belonging to a MU.

\begin{tabular}{|c|c|c|c|}
\hline & MU Yes (n: 109) & MU No (n: 287) & \\
\hline & AE agreement & AE agreement & $p$ \\
\hline \multicolumn{4}{|l|}{ Fertility preservation } \\
\hline $\begin{array}{l}\text { Discussion of the impact of treatments on fertility } \\
\text { ASCO and BCY } 4 \text { recommend addressing the subject of the impact that oncological have on } \\
\text { the whole patient of childbearing age }[4,5]\end{array}$ & $103(94.5 \%)$ & $241(84 \%)$ & 0.002 \\
\hline $\begin{array}{l}\text { Referral to a fertility specialist } \\
\text { BCY4 recommends that all women interested in preserving their fertility should be referred to } \\
\text { a specialist [4] }\end{array}$ & $90(82.6 \%)$ & $221(77 \%)$ & 0.1 \\
\hline OS is considered safe in all patients with BC [35] & $61(56 \%)$ & $119(41.5 \%)$ & 0.004 \\
\hline OS is considered safe in all patients with ER+ BC [35] & $61(56 \%)$ & $107(37.3 \%)$ & 0.0003 \\
\hline OS is considered safe in patients who have received neoadjuvant CT [35] & $69(63.3 \%)$ & $129(44.9 \%)$ & 0.0005 \\
\hline OS in patients diagnosed with BC should include letrozole and tamoxifen [35] & $70(64.2 \%)$ & $133(46.3 \%)$ & 0.0007 \\
\hline $\begin{array}{l}\text { Use of analogues during CT may be offered to all pre-menopausal patients with BC who wish } \\
\text { to preserve their fertility independent of their ER status [25] }\end{array}$ & $76(69.7 \%)$ & $173(60.3 \%)$ & 0.04 \\
\hline \multicolumn{4}{|l|}{ Pregnancy after BC } \\
\hline $\begin{array}{l}\text { Pregnancy after BC increases RR } \\
\text { Pregnancy after BC does not increase RR [36] }\end{array}$ & $85(78 \%)$ & $177(61.7 \%)$ & 0.001 \\
\hline $\begin{array}{l}\text { Pregnancy after } B C \text { increases RR only in the first } 2 \text { years following } d x \\
\text { The interval between } B C d x \text { and pregnancy does not impact patient prognosis [36] }\end{array}$ & $54(49.5 \%)$ & $125(43.5 \%)$ & 0.14 \\
\hline $\begin{array}{l}\text { Pregnancy after BC increases RR only in ER positive cancers } \\
\text { Pregnancy after BC does not increase RR, even in ER+ cancers [36] }\end{array}$ & $80(73.4 \%)$ & $151(52.6 \%)$ & 0.00009 \\
\hline $\begin{array}{l}\text { It is considered safe to temporarily interrupt } \mathrm{HT} \text { after } 18-30 \text { months to allow a pregnancy } \\
\text { The BCY } 4 \text { and Saint Gallen guides recommend a minimum } 18 \text { months of HT before considering } \\
\text { pregnancy, although prospective date is lacking }[4,27]\end{array}$ & $66(60.5 \%)$ & $137(47.7 \%)$ & 0.01 \\
\hline \multicolumn{4}{|l|}{ PABC } \\
\hline $\begin{array}{l}\text { PABC, even when adequately treated, has a worse prognosis } \\
\text { Adequately treated PABC has the same prognosis as BC without pregnancy [37] }\end{array}$ & $71(65.1 \%)$ & $134(46.7 \%)$ & 0.0005 \\
\hline $\begin{array}{l}\text { In patients diagnosed between } 28 \text { and } 33 \text { weeks, a PD is indicated } \\
\text { The ESMO guide [7] and different authors [8,38] suggest that it is always preferable to carry a } \\
\text { pregnancy to term }\end{array}$ & $69(63.3 \%)$ & $139(48.4 \%)$ & 0.004 \\
\hline $\begin{array}{l}\text { SNB with patent blue may be used, depending on the case } \\
\text { The ESMO guide [7] and Loibl [8] note the contraindication for the use of patent blue during } \\
\text { pregnancy }\end{array}$ & $79(72.5 \%)$ & $142(49.5 \%)$ & 0.00001 \\
\hline SNB with radiocolloids may be performed, depending on the case $[7,8]$ & $81(74.3 \%)$ & $125(43.5 \%)$ & $<0.0000001$ \\
\hline CT can be used safely from the second trimester on $[7,8]$ & $97(89 \%)$ & $166(57.8 \%)$ & $<0.0000001$ \\
\hline $\begin{array}{l}\text { HT may be used safely } \\
\text { Tamoxifen is teratogenic and is found to be contraindicated during pregnancy }[7,8]\end{array}$ & $96(88.1 \%)$ & $200(69.7 \%)$ & 0.00008 \\
\hline $\begin{array}{l}\text { Anti-Her2 treatment may be used safely } \\
\text { Trastuzumab passes through the placenta from the second trimester on and is found to be } \\
\text { associated with oligoamnios, and is therefore contraindicated }[7,8]\end{array}$ & $81(74.3 \%)$ & $165(57.5 \%)$ & 0.001 \\
\hline
\end{tabular}

MU: Mastology unit, AE: available evidence, tmts: treatments, OS: ovarian stimulation, PABC: pregnancy-associated BC, dx: diagnosis, PD: preterm delivery, Mx: mammogram, SNB: sentinel node biopsy, HT: hormone therapy, RT: radiation therapy, CT: chemotherapy 
More than half of those surveyed did not consider OS safe or were unaware of it, especially in those with ER positive BC, similar to the $43.2 \%$ published by Lambertini et al [13]. Regarding OS protocols in BC patients, $51.3 \%$ stated that they should include letrozole or tamoxifen, similar to that described by Sanada et al [21], who used aromatase inhibitors in up to $68.3 \%$ of patients with BC. The results of the prospective STIM trial (NTR4108) confirming the safety of these protocols are awaited [22].

$62.9 \%$ considered that the use of gonadotropin-releasing hormone $(\mathrm{GnRH})$ analogues during $\mathrm{CT}$ could be offered to all pre-menopausal patients with BC who wish to preserve their fertility, regardless of ER status. Randomised studies [23, 24] and meta-analyses [25] evaluated the efficacy of this procedure even in ER positive patients. ASCO 2018 [5] and the Consensus of Breast Cancer in young women (BCY4) [4] consider that this method should be offered to patients who are interested in fertility preservation, and who cannot or do not wish to use other methods. Lambertini et al [25] suggests that they would not be exclusive and could be offered to patients who have already used other preservation techniques. Ovarian suppression was the best known strategy $82.4 \%$, in the Lambertini survey [13]; however, in our study, only $54.8 \%$ considered it useful. This could be related to the lack of coverage of other techniques in some countries.

It is not necessary for all professionals to have a thorough understanding of every fertility preservation procedure. However, the patient of childbearing age who is going to receive cancer treatment should be informed about safety and the possibility of consultation with a fertility specialist to advise her on the different options available. It is important to acknowledge to the patient that it is desirable to preserve her fertility and to make a rapid referral.

\section{Pregnancy after BC}

In evaluating the risk posed by pregnancy after BC, $66.2 \%$ of those surveyed stated that it does not increase, $45.2 \%$ considered that it does not do so within the first 2 years of diagnosis, or in ER positive disease (58.3\%). In his survey, Lambertini [13], reported similar data: 69.6\%, $50.5 \%$ and $63 \%$, respectively. Current evidence suggests that pregnancy after BC does not increase the risk of relapse [4]. Some $62.4 \%$ of the professionals considered assisted reproductive techniques safe in a patient with a history of BC, similar to the $57.5 \%$ reported in the literature [13].

The best time to become pregnant remains controversial. Experts suggest waiting 2 years after diagnosis to start trying become pregnant [26].

In our survey, $51.3 \%$ responded that it is safe to temporarily interrupt hormone treatment after 18-30 months to allow a pregnancy, as did the 50.5\% reported by Lambertini [13]. This behaviour is supported by the BCY4 Consensus [4] and Saint Gallen 2019 [27]; however, it will be the results of the POSITIVE study (IBCSG 48-14 NCT02308085) that provides the answer on regarding its safety [28].

\section{BC during pregnancy}

Despite the fact that BC during pregnancy does not represent a worse prognosis for women [8, 29], 39.9\% of those surveyed answered yes, even when it is treated appropriately, similar to the $31.5 \%$ reported in the literature [13]. It is worth mentioning that distinct publications found that a postpartum BC diagnosis may be associated with a worse prognosis than a diagnosis during pregnancy [30].

$33.6 \%$ stated that in patients diagnosed at 28-33 weeks, a preterm birth is indicated at the start of oncological treatment; however, the greatest risk to consider is prematurity. The best option, when possible, is to carry out treatments during pregnancy and carry to term $[7,8]$.

In accordance with current evidence, sentinel node biopsy (SNB) is a procedure that can be carried out in a safe manner during pregnancy $[7,8]$. For studies using radiocolloids, some $52 \%$ of the respondents considered the use of radiocolloids safe during pregnancy; on the other hand, $55.8 \%$ contraindicated patent blue due to the potential for anaphylactic reactions [7, 8, 31].

In evaluating the safety of different adjuvant treatments, it is seen that $66.4 \%$ considered CT to be safe to start in the second trimester, which is correct, and that its use during the first trimester is associated with foetal malformations and miscarriage [7, 8].

85.6\%, $74.7 \%$ and $62.1 \%$, respectively, responded that radiation therapy, $\mathrm{HT}$ and anti-Her2 treatment should be avoided during pregnancy. Lambertini [13] published similar numbers $-76.6 \%, 76.2 \%$ and $61.9 \%$. 


\section{Knowledge according to belonging to a MU}

MUs are created to optimise the quality of patient care through better coordination and communication between different disciplines, and for advances in knowledge to be applied in a uniform manner, benefiting every patient and professional in the MU.

In 2015 [32], the SAM developed an accreditation programme based on international guidelines [33, 34]. In the completed survey, it is evident that belonging to a $\mathrm{MU}$ leads to enrichment and continuing education, such that the responses of the professionals who engaged in these were in accordance in a statistically significant manner with available evidence [4, 5, 7, 8, 27, 35-38].

In order to carry out this work, the SAM database of professionals was used. The response rate was low, though similar to other surveys [10, 12]; thus conclusions could not be extrapolated to what is happening throughout Argentina. Other limitations of the study were selection bias, which is possible given that only those professionals who are interested in the topic decided to answer.

Its strength is that it is the first study to permit evaluation of current knowledge and practices in relation to the topics in this field and the great interest that they generate.

\section{Conclusion}

Based on these results, we can conclude that the level of knowledge is comparable to the data presented in other surveys. Belonging to a MU was associated with being more up-to-date on this topic.It is necessary to continue working to train professionals in facilitating communication, information and advising patients of childbearing age who are going to receive oncological treatment so they can be informed about fertility preservation as well as the possibility of pregnancy following a BC diagnosis, and providing better care to those with BC during pregnancy.

\section{Conflicts of interest}

The authors declare no conflict of interest related to the present work.

\section{Funding}

Nothing of a financial nature was received for the execution of the present work.

\section{References}

1. SEER [https://seer.cancer.gov/statfacts/html/breast.html] Date accessed: 26/05/20

2. Meiss Kress RP, Chuit R, and Novelli JE, et al (2016) Breast cancer in Argentina: analysis from a collaborative group for the study of female breast cancer J Cancer Epi Treat 1(2) 5-16 https://doi.org/10.24218/jcet.2016.10

3. Fabiano V, Mando P, and Rizzo M, et al (2020) Breast cancer in young women presents with more aggressive pathologic characteristics: retrospective analysis from an argentine national database JCO Global Oncol 6 639-646 https://doi.org/10.1200/JGO.19.00228

4. Paluch-Shimon S, Cardoso F, and Partridge AH, et al (2020) ESO-ESMO 4th International Consensus Guidelines for Breast Cancer in Young Women (BCY4) Ann Surg Oncol 31(6) 674-696 https://doi.org/10.1016/j.annonc.2020.03.284

5. Oktay K, Harvey $\mathrm{BE}$, and Partridge $\mathrm{AH}$, et al (2018) Fertility preservation in patients with cancer: ASCO clinical practice guideline update J Clin Oncol 36 1994-2001 https://doi.org/10.1200/JCO.2018.78.1914 PMID: 29620997

6. National Comprehensive Cancer Network (NCCN) [www.nccn.org] 26/05/20

7. Peccatori FA, Azim Jr HA, and Orecchia R, et al (2013) Cancer, pregnancy and fertility: ESMO Clinical Practice Guidelines for diagnosis, treatment and follow-up Ann Oncol 24(6) vi160-vi170 https://doi.org/10.1093/annonc/mdt199 PMID: 23813932 
8. Loibl S, Schmidt A, and Gentilini O, et al (2015) Breast cancer diagnosed during pregnancy: adapting recent advances in breast cancer care for pregnant patients JAMA Oncol 1(8) 1145-1153 https://doi.org/10.1001/jamaoncol.2015.2413 PMID: 26247818

9. Patel P, Kohn T, and Cohen J, et al (2020) Evaluation of reported fertility preservation counseling before chemotherapy using the quality oncology practice initiative survey JAMA Network Open 3(7) e2010806 https://doi.org/10.1001/jamanetworkopen.2020.10806 PMID: 32678451 PMCID: 7368166

10. Quinn GP, Vadaparampil ST, and Lee J-H, et al (2009) Physician referral for fertility preservation in oncology patients: a national study of practice behaviors J Clin Oncol 27(35) 5952-5957 https://doi.org/10.1200/JCO.2009.23.0250 PMID: 19826115

11. Forman EJ, Anders CK, and Behera MA. (2010) A nationwide survey of oncologists regarding treatment-related infertility and fertility preservation in female cancer patients Fertil Steril 94 1652-1656 https://doi.org/10.1016/j.fertnstert.2009.10.008

12. Adams E, Hill E, and Watson E (2013) Fertility preservation in cancer survivors: a national survey of oncologists' current knowledge, practice and attitudes Br J Cancer 108 1602-1615 https://doi.org/10.1038/bjc.2013.139 PMID: 23579214 PMCID: 3668471

13. Lambertini M, Di Maio M, and Pagani O, et al (2018) The BCY3/BCC 2017 survey on physicians' knowledge, attitudes and practice towards fertility and pregnancy-related issues in young breast cancer patients Breast 42 41-49 https://doi.org/10.1016/j. breast.2018.08.099 PMID: 30170202

14. Rosenberg SM, Gelber S, and Gelber RD, et al (2017) Oncology physicians' perspectives on practices and barriers to fertility preservation and the feasibility of a prospective study of pregnancy after breast cancer J Adolesc Young Adult Oncol 6(3) 429-434 https://doi. org/10.1089/jayao.2017.0031 PMID: 28686476 PMCID: 5649410

15. Ruddy KJ, Gelber SI, and Tamimi RM, et al (2014) Prospective study of fertility concerns and preservation strategies in young women with breast cancer J Clin Oncol 32(11) 1151-1156 https://doi.org/10.1200/JCO.2013.52.8877 PMID: 24567428 PMCID: 4164759

16. Partridge $\mathrm{AH}$, Gelber S, and Peppercorn J, et al (2004) Web-based survey of fertility issues in young women with breast cancer J Clin Oncol 22 4174-4183 https://doi.org/10.1200/JCO.2004.01.159 PMID: 15483028

17. Llarena NC, Estevez SL, and Tucker SL, et al (2015) Impact of fertility concerns on tamoxifen initiation and persistence J Natl Cancer Inst 107(10) dvj202 https://doi.org/10.1093/jnci/djv202

18. Ruggeri M, Pagan E, and Bagnardi V, et al (2019) Fertility concerns, preservation strategies and quality of life in young women with breast cancer: baseline results from an ongoing prospective cohort study in selected European centers Breast 47 85-92 https://doi. org/10.1016/j.breast.2019.07.001 PMID: 31362134

19. Peate $M$, Meiser B, and Friedlander $M$, et al (2011) It's now or never: fertility-related knowledge, decision-making preferences, and treatment intentions in young women with breast cancer-An Australian Fertility Decision Aid Collaborative Group Study J Clin Oncol 29(10) 1670-1677 https://doi.org/10.1200/JCO.2010.31.2462 PMID: 21444865

20. Masciello MC, Bartolomew AJ, and Haslinger M, et al (2019) Physician perspectives on fertility preservation discussions with premenopausal breast cancer patients: results from a multihospital health care system Ann Surg Oncol 26(10) 3210-3215 https://doi. org/10.1245/s10434-019-07563-w PMID: 31342399

21. Sanada Y, Harada M, and Kunitomi C, et al (2019) A Japanese nationwide survey on the cryopreservation of embryos, oocytes and ovarian tissue for cancer patients J Obstet Gynaecol Res 45(10) 2021-2028 https://doi.org/10.1111/jog.14073 PMID: 31364239

22. Dahhan T, Balkenende EME, and Beerendonk CCM, et al (2017) Stimulation of the ovaries in women with breast cancer undergoing fertility preservation: alternative versus standard stimulation protocols; the study protocol of the STIM-trial Contemp Clin Trials 61 96-100 https://doi.org/10.1016/j.cct.2017.07.009 PMID: 28710053 
23. Moore HCF, Unger JM, and Phillips K-A, et al (2015) Goserelin for ovarian protection during breast-cancer adjuvant chemotherapy N Engl J Med 372(10) 923-932 https://doi.org/10.1056/NEJMoa1413204 PMID: 25738668 PMCID: 4405231

24. Leonard RCF, Adamson DJA, and Bertelli G, et al (2017) GnRH agonist for protection against ovarian toxicity during chemotherapy for early breast cancer: the Anglo Celtic Group OPTION trial Ann Oncol 28(8) 1811-1816 https://doi.org/10.1093/annonc/mdx184 PMID: 28472240

25. Lambertini M, Moore HCF, and Leonard RCF, et al (2018) Gonadotropin-releasing hormone agonists during chemotherapy for preservation of ovarian function and fertility in premenopausal patients with early breast cancer: a systematic review and meta-analysis of individual patient-level data J Clin Oncol 36(19) 1981-1990 https://doi.org/10.1200/JC0.2018.78.0858 PMID: 29718793 PMCID: 6804855

26. Cardoso F, Loibl S, and Pagani O, et al (2012) The European Society of Breast Cancer Specialists recommendations for the management of young women with breast cancer Eur J Cancer 48(18) 3355-3377 https://doi.org/10.1016/j.ejca.2012.10.004 PMID: 23116682

27. Burstein HJ, Curigliano G, and Loibl S, et al (2019) Estimating the benefits of therapy for early-stage breast cancer: The St. Gallen International Consensus guidelines for the primary therapy of early breast cancer 2019 Ann Oncol 30(10) 1541-1557 https://doi. org/10.1093/annonc/mdz235 PMID: 31373601

28. Pregnancy Outcome and Safety of Interrupting Therapy for Women with Estrogen Responsive Breast Cancer (POSITIVE) [https://clinicaltrials.gov/show/NCT02308085] Date accessed: 22/03/20

29. Amant F, von Minckwitz G, and Han SN, et al (2013) Prognosis of women with primary breast cancer diagnosed during pregnancy: results from an international collaborative study J Clin Oncol 31 2532-2539 https://doi.org/10.1200/JCO.2012.45.6335 PMID: 23610117

30. Azim Jr HA, Santoro L, and Russell-Edu W, et al (2012) Prognosis of pregnancy-associated breast cancer: a meta-analysis of 30 studies Cancer Treat Rev 38 834-842 https://doi.org/10.1016/j.ctrv.2012.06.004

31. Peccatori FA, Lambertini M, and Scarfone G, et al (2018) Biology, staging, and treatment of breast cancer during pregnancy: reassessing the evidences Cancer Biol Med 15(1) 6-13 https://doi.org/10.20892/j.issn.2095-3941.2017.0146 PMID: 29545964 PMCID: 5842335

32. McLean I, Terrier F, and Elizalde R, et al (2015) Unidades de Mastología. Fundamentos, Certificación y Acreditación. Sociedad Argentina de Mastología V01-2015.

33. National Accreditation Program For Breast Centers Standards Manual 2018 Edition (Chicago: American College of Surgeons) [Error! Hyperlink reference not valid.]

34. Biganzoli L, Fatima Cardoso F, and Marc Beishon M, et al (2020) The requirements of a specialist breast centre Breast 51 65-84 https:// doi.org/10.1016/j.breast.2020.02.003 PMID: 32217457 PMCID: 7375681

35. Kim J, Turan V, and Oktay K (2016) Long-Term safety of letrozole and gonadotropin stimulation for fertility preservation in women with breast cancer J Clin Endocrinol Metab 101(4) 1364-1371 https://doi.org/10.1210/jc.2015-3878 PMID: 26751194 PMCID: 4880171

36. Lambertini M, Kroman N, and Ameye L, et al (2018) Long-term safety of pregnancy following breast cancer according to estrogen receptor status J Natl Cancer Inst 110(4) 426-429 https://doi.org/10.1093/jnci/djx206

37. Amant F, von Minckwitz G, and Han SN, et al (2013) Prognosis of women with primary breast cancer diagnosed during pregnancy: results from an international collaborative study J Clin Oncol 31(20) 2532-2539 https://doi.org/10.1200/JCO.2012.45.6335 PMID: $\underline{23610117}$

38. Amant F, Vandenbroucke T, and Verheecke M, et al (2015) Pediatric outcome after maternal cancer diagnosed during pregnancy N Engl J Med 373(19) 1824-1834 https://doi.org/10.1056/NEJMoa1508913 PMID: 26415085 


\section{Appendix A. Survey of current practices in BC, fertility preservation and pregnancy}

\section{A) Demographic data}

1. Age: _-_-_-_-_ years.

2. Gender: _-__Female _-_-_Male

3. What is your speciality?

_-_-_ Mastology

_---_ Gynaecology

_-_-_ General surgery

Obstetrics
---- Oncology

Imaging

_-_-- Radiotherapy

Anatomical pathology

4. Are you a member of the ASM?

__-_Yes __-_- Subscriber ___-_Member __-_- Honorary __-_- Lifetime Member No

5. How would you define your regular practice?

_-_-_ Hospital/sanatorium

Private practice

Both

Other (please specify):

6. How long have you been in practice? years.

7. Do you work in a MU certified/accredited by AMS?

---- Yes

No

8. How many patients under 40 with $B C$ do you treat annually?

fewer than 10

10-50

_-_-_more than 50

9. How many patients with PABC have you seen in the last 10 years of practice?

0

1-5

6-10

more than 10 
10. Are you interested in receiving information on the topics in this survey?

-_-- Yes

---- No

---- Maybe

11. Are you interested in attending a course on the topics in this survey?

---- Yes

No

Maybe

B) BC and fertility preservation

1. How often do you discuss with the impact oncological treatment can have on future fertility with young patients with BC?

__-__ Always ____ Almost always _____ Sometimes _____ Almost never_____ Never

2. How often do you refer young patients with BC to a fertility specialist?

_____ Always _____ Almost always ____- Sometimes _____ Almost never__-_. Never

3. In cases wherein patients are not referred to a fertility specialist. Check ALL of the reasons you consider to be correct.

_-_-- Lack of Information on available methods.

No availability of fertility specialists in your work area.

You would not consider ovulation stimulation to be appropriate in these patients.

_-_ Consider that these procedures would delay starting cancer treatments.

_-_- You do not believe that it is advisable for patients with $B C$ to attempt future pregnancies.

Patient-related factors: age, parity, marital status, cancer prognosis.

-_-_ The patient does not want it.

-_-_ Other reasons: Specify

4. Which of the following fertility preservation techniques are considered useful in patients with BC? Check ALL that you consider: Embryo cryopreservation.

Oocyte cryopreservation

_-_ Ovarian tissue cryopreservation.

Use of GnRH analogues during CT.

-_- None. 
5. Check ALL statements with which you agree:

\begin{tabular}{|c|c|c|c|}
\hline & Yes & No & No response \\
\hline \multicolumn{4}{|l|}{ OS is considered safe in all patients with BC } \\
\hline \multicolumn{4}{|l|}{ OS is considered safe in patients with ER positive BC } \\
\hline \multicolumn{4}{|l|}{ OS is considered safe in patients who have received neoadjuvant CT } \\
\hline \multicolumn{4}{|l|}{ OS in patients with a BC diagnosis should include letrozole or tamoxifen } \\
\hline \multicolumn{4}{|c|}{$\begin{array}{l}\text { The use of analogues during CT can be offered to all pre-menopausal patients } \\
\text { with BC who wish to preserve their fertility independent of ER status }\end{array}$} \\
\hline \multicolumn{4}{|l|}{ The impact of CT on future fertility depends on age, drugs and dosages used } \\
\hline $\begin{array}{l}\text { The risk of amenorrhoea following } \mathrm{CT} \text { is greater in women }<30 \text { years } \\
\text { compared to women }>40 \text { years }\end{array}$ & & & \\
\hline
\end{tabular}

OS; Ovarian stimulation, pts; patients, BC; breast cancer, ER; oestrogen receptors, CT; chemotherapy, NR; no response

\section{C) Pregnancy after BC}

\begin{tabular}{|l|l|l|l|}
\hline & \multicolumn{1}{|c|}{ Yes } & No & NR \\
\hline Pregnancy after BC increases RR & & & \\
\hline Pregnancy after BC increases RR only in the first 2 years following dx & & & \\
\hline Pregnancy after BC increases RR only in ER+ cases & & & \\
\hline $\begin{array}{l}\text { It is considered safe to temporarily interrupt HT after 18-30 months to allow } \\
\text { a pregnancy }\end{array}$ & & & \\
\hline Lactation after BC is considered safe & & & \\
\hline ARTs are considered safe in patients who have had BC & & & \\
\hline
\end{tabular}

BC: Breast cancer, RR: risk of recurrence, dx: diagnosis, ER: oestrogen receptors, HT: hormone therapy, ART: assisted reproduction techniques, NR: no response

\section{D) PABC}

\begin{tabular}{|l|l|l|l|}
\hline & \multicolumn{1}{|c|}{ Yes } & No & NR \\
\hline PABC, even when adequately treated, has a worse prognosis & & & \\
\hline In patients diagnosed between 28 and 33 weeks, a PD is indicated & & & \\
\hline Mx may be used with abdominal protection & & & \\
\hline Conservative surgery may be considered, depending on the case & & & \\
\hline The SNB with patent blue may be performed, depending on the case & & & \\
\hline SNB with radiocolloids may be performed, depending on the case & & & \\
\hline RT during pregnancy is safe & & & \\
\hline CT may be used safely in each trimester & & & \\
\hline CT may be used safely from the second trimester on & & & \\
\hline HT may be used safely & & & \\
\hline Anti-Her2 treatment may be used safely & & & \\
\hline
\end{tabular}

PABC: Pregnancy-associated BC, dx: diagnosis, PD: preterm delivery, Mx: mammogram, SNB: sentinel node biopsy, $\mathrm{RT}$ : radiation therapy, CT: chemotherapy, NR: no response

Thank you very much for your responses and time. 


\section{Appendix B. E-mail format used to request participation in the survey}

Dear colleague:

We would like to request your assistance by responding to this anonymous survey about current practices in breast cancer, fertility preservation and pregnancy, the results of which will be used to conduct a scientific study. It will not take longer than 10 minutes to complete.

We appreciate your time and collaboration.

Sincerely,

Dr Gabriela Candás

Dr Alejandra García

Link to the survey

If you have already completed the survey, please disregard this message. Thank you very much. 